\title{
Sleep disturbances and non-cyclical breast pain: where to break the vicious cycle?
}

\author{
Pelin Basım ${ }^{1}$ D $\cdot$ Sena Tolu ${ }^{2}$ D
}

Received: 30 January 2021 / Revised: 29 March 2021 / Accepted: 18 May 2021 / Published online: 25 May 2021

(c) The Author(s), under exclusive licence to Springer Nature Switzerland AG 2021

\begin{abstract}
Purpose This study aimed to assess the sleep quality of patients with the complaint of non-cyclical breast pain (NCBP), compare them to a healthy control group, and analyze the interrelationship of sleep quality with pain, anxiety, depression, and quality of life.

Methods This cross-sectional study was conducted in consecutive women presenting to the general surgery clinic between May 2020 and December 2020. Patients diagnosed with NCBP formed one group for study and 44 receiving routine wellwoman care formed the control group. Evaluations were undertaken using the Nottingham Health Profile (NHP), short-form McGill Pain Questionnaire (SF-MPQ), Hospital Anxiety and Depression Scale (HADS), and Pittsburgh Sleep Quality Index (PSQI).

Results Of 160 consecutive patients, 116 were diagnosed with NCBP and 44 controls. Poor sleep quality (PSQI $>5$ ) was present in 59\% $(n=69)$ of the women with NCBP and 38\% $(n=17)$ of the controls $(p=0.018)$. According to PSQI global score, overall sleep quality was significantly lower in the NCBP group compared to the control group $(\mathrm{p}<0.007)$. Sleep latency, sleep duration, and daytime dysfunction were the major components determining the PSQI global score $(\mathrm{p}=0.004$, $p=0.004$, and $p<0.001$, respectively). The correlation matrix revealed a statistically significant correlation between the HAD-A, HAD-D, and SF-MSQ and NHP subgroups and PSQI global score in the NCBP group $(\mathrm{p}<0.001)$ whereas this significant correlation was detected with only the NHP subgroups among the controls.

Conclusions A considerable proportion of NCBP patients, regardless of sensory or affective characteristics and trajectory of pain, experience significant sleep disturbances. Further studies should be conducted to evaluate the existence of central sensitization syndrome in NCBP patients to determine the required pharmacological treatment.
\end{abstract}

Keywords Non-cyclical breast pain $\cdot$ Sleep disorders $\cdot$ Anxiety $\cdot$ Depression $\cdot$ Quality of life $\cdot$ Central sensitization

\section{Introduction}

Breast pain (BP) (mastalgia) is one of the leading complaints among women aged $30-50$ years and constitutes a multi-faceted problem prompting women to seek medical evaluation and treatment. During their lifetimes, $70 \%$ of women need to

Pelin Basim

pelinakbaba@gmail.com

Sena Tolu

dr.sena2005@gmail.com

1 Department of General Surgery, Medipol University, TEM Avrupa Otoyolu Göztepe Çıkışı No: 1, 34214 Bagcilar, Istanbul, Turkey

2 Department of Physical Medicine and Rehabilitation, Medipol University, Istanbul, Turkey consult a physician due to BP [1]. With the increase in breast cancer awareness in this population, there has also been an increasing in the number of women presenting to hospitals to seek medical advice concerning their BP complaints [2]. BP manifests in cyclical and non-cyclical forms classified according to the relationship of the disease with menstrual cycle, with the former being often bilateral, diffuse, and poorly localized and experienced worse by the patient before the menstrual period and usually affecting the upper outer quadrant and radiating to the upper arm and armpit [3-5]. Cyclical breast pain (CBP) is most commonly encountered in the young age group during the luteal phase due to high estrogen and low progesterone levels; therefore, an imbalanced ratio of sex hormones results in breast parenchymal edema $[1,6]$. On the other hand, non-cyclical breast pain (NCBP) has no proven relationship with the menstrual cycle 
and is most commonly seen in the elderly patient group. The pain is mostly described by the patients as sharp, burning, constant, and usually unilateral, radiating to the ipsilateral shoulder. Several other factors have also been investigated in terms of their causal relationship with NCBP, including breast size, smoking habits, cysts, periductal mastitis, stretching of Cooper's ligaments, traumatic fat necrosis, and diabetic mastopathy; nevertheless, the majority of patients do not present with any of these features [7]. Although found in a small proportion of affected women, irregular menstrual cycles, oral contraceptives, hormonotherapies, psychosomatic factors, emotional distress, and some drugs (cardiovascular agents, psychotropic drugs, etc.) are considered to be related to NCBP $[1,7]$.

In a patient presenting with $\mathrm{BP}$, the first critical step is to exclude the possibility of breast cancer. BP is the primary symptom in $2-7 \%$ of the patients in newly diagnosed breast cancer. Regardless of the age and physical status of the patient, a thorough physical examination and appropriate screening radiological methods should be used to exclude any possibility of breast cancer [8-10]. Another important step is to distinguish radiating BP (extra-mammary pain) from true BP. The most common extra-mammary pain syndromes are chest wall pain caused by costochondritis and radicular pain due to arthritis, fibromyalgia, and other musculoskeletal pathologies. Cardiovascular, hepatobiliary, and neurological pathologies are uncommon causes of BP but they should still be taken into consideration because of their high morbidity rates [7].

Considering persistent pain problems, psychological factors and sleep problems are some of the most frequent symptoms that have been associated with a decline in the well-being and quality of life (QoL) of these patients. Some studies report that poor sleep quality, sleep onset difficulties, and difficulty in awakening are clearly associated with depression and anxiety whereas others claim that sleep disturbance is a remarkable risk factor that aggravates the disease state and threatens the general well-being of the patient. While numerous studies have evaluated sleep disturbances in chronic diseases characterized by significant pain, including fibromyalgia, temporomandibular joint disorders, migraine and tension-type headaches, and irritable bowel syndrome, there remains a gap in the literature concerning research on sleep disturbances related to BP [11-17]. A growing body of knowledge about these functional somatic syndromes characterized by unexplained pain disproportionate to the underlying pathophysiology currently hypothesizes a complex syndrome, known as central sensitization syndrome (CSS) associated with sleep disturbances complicated with many pathways to enhance pain transmission and perception $[11,14,17]$. Poor sleep quality has been proven to be mainly associated with pain intensity itself, but QoL, global wellbeing, and anxiety and depression levels of the individuals have also been considered to have a remarkable impact on sleep quality. There are a few studies reporting that women with $\mathrm{BP}$ are more prone to developing depression and anxiety, and their QoL is negatively affected to a certain degree compared to the healthy population [2].

The aims of this cross-sectional study were to assess sleep quality in the patients with NCBP, determine the association of sleep disorders with anxiety, depression and pain, and analyze the impact of QoL on sleep quality.

\section{Methods}

\section{Study design and patients}

The study was conducted with a cross-sectional design. To form the study groups, 647 regularly menstruating premenopausal women aged 18 to 45 years consecutively presenting to the general surgery clinic between May 2020 and December 2020 with similar demographic characteristics, either admitted for routine breast control $(n=217)$ or with the complaint of NCBP for at least six months $(n=430)$, were screened. Forty-four individuals from the control group were found to meet the inclusion criteria of the study. On the other hand, of the 430 patients with NCBP, 314 patients were excluded from the study according to exclusion criteria and 116 were eligible to participate in the study. A total of 160 women were enrolled in the study.

The exclusion criteria were as follows: (i) age $<18$ and $>45$ years, (ii) a history of breast biopsy or aesthetical breast operation due to benign breast disease or breast cancer, (iii) refusal to participate in the study, (iv) any diagnosis of medically unexplained somatic disorders, such as fibromyalgia, restless legs syndrome, chronic fatigue syndrome, dysmenorrhea, temporomandibular joint disorders, migraine or tension headaches, irritable bowel syndrome, multiple chemical sensitivities, previous neck injury including whiplash, anxiety or panic attacks and depression, and use of any medication for the treatment of these disorders, and (v) any diagnosis of cognitive dysfunction or psychiatric disorders and receiving psychiatric treatments.

All participants underwent a physical breast examination by the same breast surgeon to detect any lump in the breast and any associated nipple retraction or discharge and were evaluated with appropriate radiological breast imaging modalities, including ultrasound, mammography, and magnetic resonance imaging (MRI) of the breast. All the participants of the study were also evaluated in the physical medicine and rehabilitation clinic of the same hospital by the same physiatrist to eliminate the possibility of a musculoskeletal system disorder causing breast pain.

A total of 116 patients with NCBP and 44 individuals from the control group that met the inclusion criteria were 
enrolled in the study. Ethical approval was granted from the Ethics Committee of İstanbul Medipol University on May 14, 2020, with the reference number 10840098-604.01.01E.15398/389. A written informed consent was obtained from each participant. The study was conducted in accordance with the principles of the Declaration of Helsinki.

\section{Data collection and questionnaires}

Information on demographic characteristics, such as age, height and weight, marital status, employment status, education level, monthly income, smoking status, and medical comorbidities, was obtained from the participants.

QoL assessment was performed using the Nottingham Health Profile (NHP) which consists of two parts. The first part is a 38-item questionnaire that assesses the domains of sleep, physical mobility, energy, pain, emotional reactions, and social isolation of the analyzed individual (NHP-1). Items in each section are rated in terms of relative importance and rescaled to a range of 0 to 100 . The second part of NHP contains seven key components related to the areas of life most affected by health: employment, household activities, social life, home life, sex life, hobbies and interests, and holidays (NHP-2). The participants who are being tested are asked to specify whether or not their present health status has affected their lives in the corresponding areas. Due to its simple and easily understood wording and practical application, NHP has been used to evaluate the effects of many chronic conditions on QoL. The current study used the Turkish version of NHP, which was validated in 2000, for the measurement of QoL by perceived health status in all chronic diseases. The Turkish version was previously reported to have high internal consistency (Cronbach's $\alpha=0.87)$ and reliability (0.88), similar to the original version [18].

The assessment of the anxiety and depression levels of the patients was performed using the Turkish version of the Hospital Anxiety and Depression Scale (HADS), a simply administered form of 14-item Likert-type checklist, to which patients respond based on a four-point scale (from 0 to 3 ) to describe their obvious symptoms within the last week. With seven questions concerning anxiety and a further seven questions related to depression, HADS is one of the most commonly used validated screening questionnaires in medical settings with good psychometric properties [19].

The Pittsburgh Sleep Quality Index (PSQI) is a global measurable instrument which assesses sleep quality and disturbances during the previous month in a self-reported manner. Nineteen separate sections define a total of seven component scores (subjective sleep quality, sleep latency, sleep duration, habitual sleep efficiency, sleep disturbances, use of sleeping medication, and daytime dysfunction) with open-ended questions. The score of each question ranges from 0 to 3, with higher scores representing more evident sleep disturbances. The sum of the scores of these seven components returns a single score representing the overall sleep quality [20].

For the patients with NCBP, data were recorded using a specially designed breast pain questionnaire, namely the short-form McGill Pain Questionnaire (SF-MPQ). Modified by Melzack in 1987 for pragmatic reasons to improve utility in clinical settings, SF-MPQ consists of three parts (a visual analog scale (VAS) of pain intensity, a present pain intensity score (PPI), and a verbal part with the subscaling measures of the severity of 15 descriptive features). The subgroups of the verbal part are associated with individual pain perception rated on an intensity Likert scale from 0 ("none") to 3 ("severe") with a possible total score range of 0 to 45 . The total pain score describes the overall pain intensity, with higher scores indicating greater pain perception. The 15 descriptors are subdivided into two independent analytic factors, with the first 11 being referred to as sensory, describing the nociceptive pain self-experience of the respondent, and the remaining four being referred to as affective, describing the emotional impact of nociceptive pain experience [21].

\section{Statistical analysis}

The power analysis for the mean sleep quality differences in between the two groups was performed using $\mathrm{G}$ power 3.1.6 for Windows (Heinrich-Heine-Universität Düsseldorf, Düsseldorf, Germany). The minimum required size of the study population was calculated to be 152 subjects in for a large effect size with at the $95 \%$ confidence interval for $\alpha=0.05$. The group sample sizes were determined pragmatically with all patients agreeing to participate in the study over the 7-month period.

Data were analyzed using IBM SPSS for Windows, version 23.0 (IBM Corp. Armonk, NY, USA). The Shapiro-Wilk test was used to evaluate the normality of data. Frequency, percentage, mean, median, standard deviation, minimum, and maximum values were used for descriptive statistics. In paired group comparisons, we used the chisquare test for categorical variables, the independent-samples $t$ test for normally distributed distribution continuous data, and the Mann-Whitney U test in other cases. Correlations were evaluated using Pearson's or Spearman's rank correlation analyses. A $p$ value of $<0.05$ was considered statistically significant.

\section{Results}

A total of 160 women consisting of 116 patients with NCBP and 44 individuals without any breast complaint admitted to general surgery clinic for regular breast examination within 
the specified time interval with similar demographic characteristics were enrolled in the study. The demographic and clinical characteristics of the study population are given in Table 1. With the exception of NHP-1 and 2 scoring, there were no statistically significant differences in any of the parameters assessed between the two groups. Among the subgroups of NHP-1, the pain and sleep scores were found to be significantly higher in the NCBP group compared to the control group ( $<<0.001$ for both) (Table 1).

Table 2 shows the comparison of sleep quality between the NCBP and control groups. The overall sleep quality described by PSQI global was significantly impaired in the patient group compared to the control group $(\mathrm{p}<0.007)$. Sleep latency, sleep duration, and daytime dysfunction were the major components determining the PSQI global score $(\mathrm{p}=0.004, \mathrm{p}=0.004$, and $\mathrm{p}<0.001$, respectively). Although there was a significant relationship between the overall sleep quality score indicated by PSQI-global and the NCBP disease state, the use of sleep medication did not significantly differ between the two groups (Table 2).

Table 3 presents the comparison of sleep quality between the NCBP and control groups based on clinical parameters. Poor sleep quality (PSQI $>5)$ was present in $59 \%(n=69)$ of the patients with NCBP and $38 \%(n=17)$ of the controls $(\mathrm{p}=0.018)$. In the NCBP group, body mass index (BMI), HAD-A and HAD-D scores, SF-MSQ subgroup scores (sensory and affective dimensions), total breast pain score, VAS-pain and PPI, and NHP-1 and NHP-2 scores were statistically significant higher and associated with poor sleep quality ( $p<0.001$ for all) whereas in the control group, only NHP-1 and NHP-2 showed a significant difference in terms of poor sleep quality (Table 3 ).

Table 4 shows a further correlation analysis of the clinical parameters with the PSQI global score. This correlation matrix revealed a statistically significant correlation between the scores of HAD-A, HAD-D, SF-MSQ, and NHP subgroups and the PSQI global score in the NCBP group ( $<<0.001)$, whereas this significant correlation was detected with only the NHP subgroups among the controls. Furthermore, the PSQI global score had no significant correlation with the pain and emotional reaction subgroups of NHP-1 in the control group, but it was significantly correlated with all the subgroups of NHP-1 in the patients with $\operatorname{NCBP}(p<0.001)($ Table 4).

\section{Discussion}

In the current study, we analyzed sleep disturbances and other related parameters, namely pain intensity, QoL, and anxiety/depression levels of the female individuals with and without NCBP. Although most studies on mastalgia have been conducted with patient populations suffering from
CBP, there are a few series with large patient populations revealing that the majority of patients complain of NCBP, which is not related to the menstrual cycle. Contrary to $\mathrm{CBP}$, which is well known to be associated with hormonal imbalance, the etiopathogenesis of NCBP is very obscure, with many theories signaling the involvement of psychosocial factors associated with chronic sleep disturbances, namely high stress level, anxiety, and depression [22-25]. Furthermore, NCBP and associated poor sleep quality are also characterized by a high ratio of unresponsiveness to applied medical therapies. For example, Khan et al. reported 56\% unresponsiveness to drug therapy among NCBP patients [26]. Persistent severe NCBP resistant to ordinary BP medications, including acetaminophen, non-steroidal antiinflammatory drugs, tamoxifen, danazol, bromocriptine, and evening prime rose oil, has led researchers to investigate other treatment modalities, such as steroid injections fortified with local anesthetics, psychiatric drug therapy targeting underlying psychopathologies, and psychoeducative therapies $[26,27]$.

The current study showed that according to NHP and PSQI, women with NCBP suffered from a significantly impaired QoL and experienced significantly higher sleep disturbances compared to their counterparts without BP. On the other hand, when we analyzed the factors affecting sleep quality, the results showed that QoL had a clear impact on sleep quality in both groups but this parallelism represented a much higher significance including all parameters of QoL in NCBP patients. Such a high rate of significance was only seen between the physical activity and energy subgroups of QoL index and sleep quality among the controls. In addition, approximately $60 \%$ of the study participants suffering from NCBP also complained of poor sleep quality, especially difficulty in falling asleep, reduced sleep duration, and daytime dysfunction due to sleep deprivation. This inference can be interpreted to indicate that in NCBP patients, suffering from pain disrupts sleep pattern as well as QoL. These results are expected since many painful, debilitating disease states have been found to be related to disturbed sleep habits [28-31]. A multifaceted complex pattern of neurologic mechanisms, including the psychoactive state of the individual, may be responsible for the causal relationship between chronic pain and sleep disturbances. Functional changes in raphe magnus cells in the brain, which are the main modulators of pain and arousal in human body, may be a definitive part of this complex system [28].

A surprising result of the study was that there were no differences in the anxiety and depression levels of the NCBP and control groups. In contrast to previous studies referring to an exaggerated stress perception in patients with NCBP compared to healthy individuals, we did not determine the psychoactive state of the patient as a primary and distinguishing factor for our patients' pain intensity and character 
Table 1 Demographic, clinical, and socioeconomic data of the participants

\begin{tabular}{|c|c|c|c|}
\hline & $\begin{array}{l}\text { Control group } \\
(\mathrm{n}=44)\end{array}$ & $\begin{array}{l}\text { NCBP group } \\
(\mathrm{n}=116)\end{array}$ & $\mathrm{p}$ \\
\hline Age, years $($ mean $\pm S D)$ & $34.5 \pm 6.6$ & $35.1 \pm 7.1$ & $0.637^{*}$ \\
\hline BMI, $\mathrm{kg} / \mathrm{m}^{2}($ mean $\pm \mathrm{SD})$ & $26.0 \pm 1.9$ & $25.6 \pm 2.2$ & $0.282^{*}$ \\
\hline Educational background, n (\%) & & & 0.943 II \\
\hline Literate & $2(4.5)$ & $5(4.3)$ & \\
\hline Primary/secondary school & $8(18.2)$ & $17(14.7)$ & \\
\hline High school & $15(34.1)$ & $44(37.9)$ & \\
\hline University & $19(43.2)$ & $50(43.1)$ & \\
\hline Employment status, n (\%) & & & $0.492 \mathbb{I}$ \\
\hline Housewife & $15(34.1)$ & $51(44)$ & \\
\hline Public official & $10(22.7)$ & $20(17.2)$ & \\
\hline Private sector employee & $19(43.2)$ & $45(38.8)$ & \\
\hline Income status, n (\%) & & & 0.954 II \\
\hline$<5.000$ & $3(6.8)$ & $9(7.8)$ & \\
\hline $5000-10,000$ & $15(34.1)$ & $37(31.9)$ & \\
\hline$>10,000$ & $26(59.1)$ & $70(60.3)$ & \\
\hline Smoking habit, yes n (\%) & $22(50)$ & $56(48.3)$ & 0.846 I \\
\hline HADs-total, median (min-max) & $16(9-30)$ & $16(6-36)$ & 0.896 ‡ \\
\hline HADs-anxiety & $8(2-18)$ & $8(2-19)$ & $0.206 t$ \\
\hline HADs-depression & $8.5(4-14)$ & $8(2-19)$ & 0.396 € \\
\hline McGill Pain Questionnaire, median (min-max) & & & NA \\
\hline Sensory dimension & & $9(4-18)$ & \\
\hline Affective dimension & & $3(1-9)$ & \\
\hline Total breast pain score & & $12(5-26)$ & \\
\hline VAS-pain & & $40(10-90)$ & \\
\hline PPI & & $2(1-4)$ & \\
\hline Nottingham Health Profile Part 1, median (min-max) & $45.21(0-295.38)$ & $80.30(10.49-406.64)$ & 0.001 z \\
\hline Physical mobility & $0(0-52.37)$ & $0(0-67.16)$ & $0.157 \mathrm{t}$ \\
\hline Pain & $0(0-33.77)$ & $24.13(5.83-83.68)$ & $<0.001 \mathrm{t}$ \\
\hline Sleep & $0(0-50.37)$ & $16.10(0-100)$ & $<0.001 \mathrm{t}$ \\
\hline Energy & $0(0-63.20)$ & $0(0-100)$ & $0.871 \mathrm{t}$ \\
\hline Social isolation & $0(0-77.47)$ & $0(0-100)$ & $0.251 \mathrm{t}$ \\
\hline Emotional reactions & $11.24(0-54.37)$ & $12.98(0-64.38)$ & $0.501 \mathrm{t}$ \\
\hline Nottingham Health Profile Part 2, median (min-max) & $1(0-5)$ & $2(0-6)$ & 0.004 € \\
\hline Comorbid disease, $\mathrm{n}(\%)$ & & & NA \\
\hline Thyroid disease & $1(2.3)$ & $6(5.2)$ & \\
\hline Diabetes mellitus & $1(2.3)$ & $3(2.6)$ & \\
\hline Gut & 0 & $1(0.9)$ & \\
\hline Hypertension & 0 & $4(3.4)$ & \\
\hline Chronic venous insufficiency & 0 & $1(0.9)$ & \\
\hline Inflammatory bowel disease (ulcerative colitis) & 0 & $1(0.9)$ & \\
\hline Gynecological problems (PCOS, endometriosis) & $2(4.6)$ & 0 & \\
\hline Anemia & 0 & $1(0.9)$ & \\
\hline Insulin resistance & 0 & $2(1.7)$ & \\
\hline Urticaria & $1(2.3)$ & 0 & \\
\hline Deep vein thrombosis & 0 & $1(0.9)$ & \\
\hline
\end{tabular}

$\mathrm{p}<0.05$ was considered statistically significant. Statistically significant differences are indicated in bold $B M I$, body mass index; $n$, number of subjects; NA, not applicable; HADs, Hospital Anxiety and Depression Scale; VAS, visual analog scale; $P P I$, present pain intensity

*Independent samples t test

"Pearson Chi-Square test

${ }^{t}$ Mann-Whitney U test 
Table 2 Comparison of sleep quality between the mastalgia and control groups

\begin{tabular}{|c|c|c|c|c|c|c|c|c|c|}
\hline & \multicolumn{4}{|l|}{ Control group } & \multicolumn{4}{|l|}{ NCBP group } & \multirow[t]{2}{*}{$\mathrm{p}$} \\
\hline & $\begin{array}{l}\text { Median (min- } \\
\max )\end{array}$ & $\begin{array}{l}\mathrm{PSQI} \leq 1 \\
\mathrm{n}(\%)\end{array}$ & $\begin{array}{l}\mathrm{PSQI}>1 \\
\mathrm{n}(\%)\end{array}$ & $\begin{array}{l}\mathrm{PSQI}>5 \\
\mathrm{n}(\%)\end{array}$ & $\begin{array}{l}\text { Median (min- } \\
\max )\end{array}$ & $\begin{array}{l}\mathrm{PSQI} \leq 1 \\
\mathrm{n}(\%)\end{array}$ & PSQI > 1 n (\%) & $\begin{array}{l}\mathrm{PSQI}>5 \\
\mathrm{n}(\%)\end{array}$ & \\
\hline $\begin{array}{l}\text { P1 Subjective } \\
\text { sleep quality }\end{array}$ & $1(0-3)$ & $34(77.2)$ & $10(22.8)$ & & $1(0-3)$ & $82(70.7)$ & $34(29.3)$ & & 0.333 \\
\hline P2 Sleep latency & $0(0-2)$ & $40(90.9)$ & $4(9.1)$ & & $1(0-3)$ & $88(75.9)$ & $28(24.1)$ & & 0.004 \\
\hline P3 Sleep duration & $0(0-2)$ & $40(90.9)$ & $4(9.1)$ & & $1(0-3)$ & $88(75.9)$ & $28(24.1)$ & & 0.004 \\
\hline $\begin{array}{l}\text { P4 Habitual sleep } \\
\text { efficiency }\end{array}$ & $1(0-2)$ & $37(84.1)$ & $7(15.9)$ & & $1(0-3)$ & $95(81.9)$ & $21(18.1)$ & & 0.221 \\
\hline $\begin{array}{l}\text { P5 Sleep distur- } \\
\text { bance }\end{array}$ & $1(0-2)$ & $29(65.9)$ & $15(34.1)$ & & $1(0-3)$ & $65(56)$ & $51(44)$ & & 0.274 \\
\hline $\begin{array}{l}\text { P6 Use of sleep } \\
\text { medication }\end{array}$ & $0(0-2)$ & 43 (97.7) & $1(2.3)$ & & $0(0-3)$ & $107(92.2)$ & $9(7.7)$ & & 0.058 \\
\hline $\begin{array}{l}\text { P7 Daytime dys- } \\
\text { function }\end{array}$ & $0(0-2)$ & $40(90.9)$ & $4(9.1)$ & & $1(0-2)$ & $86(74.2)$ & $30(25.9)$ & & $<0.001$ \\
\hline PSQI-global & $3.5(0-15)$ & & & $17(38.5)$ & $6(0-19)$ & & & 69 (59.6) & 0.007 \\
\hline
\end{tabular}

Data given as median (min-max)

$p<0.05$ was considered statistically significant. Statistically significant differences are indicated in bold

*Mann-Whitney U test

detected by the pain inventory [27]. Although it has been previously reported that NCBP patients are more prone to developing different psychological disorders, including somatization, self-esteem, minor or major depression, and anxiety and panic disorders, the question of which condition triggers the other remains [1, 2, 27]. From another point of view, in most syndromes characterized by chronic pain, psychoeducation seems to be effective in diminishing the intensity of pain with some improvement of the underlying stress level [8, 11, 12, 16]. However, this does not indicate that the main source of NCBP is stress itself considering that in contemporary society, psychodynamic therapies are reported to be effective in reducing pain in many inflammatory, infectious, and neoplastic diseases as a second-line treatment in medical practice $[8,11,14,31]$.

A second interesting result of our study is that anxiety and depression had no significant relationship with sleep quality in the control group, but both significantly negatively affected sleep quality in the patients with NCBP. There was also a statistically significant correlation between the HADA, HAD-D, SF-MSQ, and NHP-1 and NHP-2 subgroup scores and PSQI in the NCBP group whereas this correlation could only be shown between the NHP-1 and NHP-2 subgroup scores and PSQI in the control group. According to these findings, the pain itself, the psychological state, and QoL of these patients are part of a vicious cycle, in which they are either a cause or a result of poor sleep quality, as previously described in many other chronic pain disorders $[11,12,14,15]$. From another point of view, although the overall QoL seemed to affect all aspects of sleep characteristics in both the NCBP and control groups, the psychological status was found to be a significant determinant factor in the sleep quality of only the patients with NCBP. This result is partially in agreement with previous findings indicating that anxiety is a form of biological stimulant which fortifies perceived pain intensity, especially in chronic pain syndromes without underlying organ dysfunction [27, 28]. We can explain our findings with a multidirectional mechanism among NCBP, anxiety and/or depression, QoL, and sleep quality. An important point of this study can be considered that pain was not only used as a subjective determinant but was also expressed based on a numerical scale using SFMSQ; therefore, we can state that there was a negative correlation between the degree and character of pain and sleep quality. These findings may help make an inference about a hypothetical intervention to break the circadian pathways impacting on sleep quality in NCBP patients.

As described in NCBP, a high stress level is also known to play an irrefutable role in many painful disease states characterized by unenlightened pathophysiologies, including temporomandibular joint disorders, fibromyalgia, restless legs syndrome, irritable bowel syndrome, chronic pelvic pain, and tension headaches [28, 31]. Many studies have been undertaken to define the stress-pain-mood disorder axis in these conditions. This theory was first put forward in 2011 by Genc et al., who hypothesized that BP and fibromyalgia were coexisting pain disorders that would be difficult to treat if other chronic pain disorders were overlooked [32]. Although this was an exciting hypothesis, their study had certain limitations: Firstly, BP was not divided into subgroups, and all patients with BP, cyclical or noncyclical, were considered to have the same etiopathogenesis. 
Table 3 Comparison between good and poor sleep based on clinical parameters for the NCBP and control groups

\begin{tabular}{|c|c|c|c|c|c|c|c|}
\hline \multirow[b]{2}{*}{ Study group, n (\%) } & \multicolumn{2}{|l|}{$\begin{array}{l}\text { Good sleep } \\
(\mathrm{PSQI} \leq 5 ; \mathrm{n}=74)\end{array}$} & \multicolumn{2}{|l|}{$\begin{array}{l}\text { Poor sleep } \\
(\mathrm{PSQI}>5 ; \mathrm{n}=86)\end{array}$} & \multirow{2}{*}{$\begin{array}{l}\mathrm{p}^{\circ} \\
0.018 \mathrm{II}\end{array}$} & \multirow[t]{2}{*}{$\mathrm{p}^{1}$} & \multirow[t]{2}{*}{$\mathrm{p}^{2}$} \\
\hline & $\begin{array}{l}\text { Control group } \\
\mathrm{n}=27(37 \%)\end{array}$ & $\begin{array}{l}\text { NCBP group } \\
n=47(64 \%)\end{array}$ & $\begin{array}{l}\text { Control group } \\
\mathrm{n}=17(20 \%)\end{array}$ & $\begin{array}{l}\text { NCBP group } \\
n=69(80 \%)\end{array}$ & & & \\
\hline Age, mean \pm SD & $34.6 \pm 6.7$ & $36.2 \pm 6.4$ & $34.5 \pm 6.6$ & $34.4 \pm 7.5$ & & $0.967 \mathrm{t}$ & $0.190 \mathrm{t}$ \\
\hline $\mathrm{BMI}$, mean $\pm \mathrm{SD}$ & $26.0 \pm 2.1$ & $25.1 \pm 1.8$ & $25.9 \pm 1.5$ & $25.9 \pm 2.4$ & & $0.793 \mathrm{z}$ & $0.046 t$ \\
\hline \multicolumn{8}{|l|}{$\begin{array}{l}\text { HADs-total, median } \\
\quad(\min -\max )\end{array}$} \\
\hline HADs-anxiety & $7(2-18)$ & $6(2-11)$ & $8(4-16)$ & $11(3-19)$ & & $0.332 *$ & $<0.001 *$ \\
\hline HADs-depression & $8(6-14)$ & $7(2-12)$ & $9(4-14)$ & $9(3-19)$ & & $0.494 *$ & $<0.001 *$ \\
\hline $\begin{array}{l}\text { Nottingham Health } \\
\text { Profile Part 1, median } \\
\text { (min-max) }\end{array}$ & $37.06(0-72.59)$ & $43.43(10.49-150.95)$ & $78.39(24-295.38)$ & $114.22(12.91-406.64)$ & & $<0.001^{*}$ & $<0.001 *$ \\
\hline Physical mobility & $0(0-21.99)$ & $0(0-21.30)$ & $20.50(0-52.37)$ & $0(0-67.16)$ & & $<0.001 *$ & $<0.001 *$ \\
\hline Pain & $0(0-33.77)$ & $21.21(5.83-46.74)$ & $0(0-8.96)$ & $33.09(5.83-83.68)$ & & $0.027 *$ & $<0.001 *$ \\
\hline Sleep & $0(0-16.10)$ & $0(0-100)$ & $12.57(0-50.37)$ & $21.70(0-100)$ & & $0.002 *$ & $<0.001 *$ \\
\hline Energy & $0(0-39.20)$ & $0(0-63.20)$ & $24(0-63.20)$ & $0(0-100)$ & & $<0.001 *$ & $<0.001 *$ \\
\hline Social isolation & $0(0-37.98)$ & $0(0-61.50)$ & $0(0-77.47)$ & $0(0-100)$ & & $0.012 *$ & $<0.001 *$ \\
\hline Emotional reactions & $10.47(0-46.19)$ & $7.08(0-43.51)$ & $16.21(0-54.37)$ & $20.23(0-64.38)$ & & $0.716^{*}$ & $<0.001 *$ \\
\hline $\begin{array}{l}\text { Nottingham Health } \\
\text { Profile Part 2, median } \\
\text { (min-max) }\end{array}$ & $1(0-2)$ & $1(0-3)$ & $2(0-5)$ & $2(0-6)$ & & $0.026 *$ & $<0.001 *$ \\
\hline \multicolumn{8}{|l|}{$\begin{array}{l}\text { McGill Pain Question- } \\
\text { naire, median (min- } \\
\text { max) }\end{array}$} \\
\hline Sensory dimension & & $9(4-16)$ & & $11(4-18)$ & & & $0.022 *$ \\
\hline Affective dimension & & $2(1-7)$ & & $4(1-9)$ & & & $0.006 *$ \\
\hline Total breast pain score & & $11(5-22)$ & & $14(5-26)$ & & & $0.007 *$ \\
\hline VAS-pain & & $30(10-60)$ & & $50(10-90)$ & & & $<0.001 *$ \\
\hline PPI & & $2(1-3)$ & & $3(1-4)$ & & & $<0.001 *$ \\
\hline
\end{tabular}

*Mann-Whitney U test; đIPearson's chi-Square test; independent samples t test. p $<0.05$ was considered statistically significant. Statistically significant differences are indicated in bold

$B M I$, body mass index; PSQI, Pittsburgh Sleep Quality Index; HADs, Hospital Anxiety and Depression Scale; VAS, visual analog scale; PPI, present pain intensity

$\mathrm{p}^{\circ}$ : significance between control and NCBP groups

$\mathrm{p}^{1}$ : significance between good and poor sleepers in control group

$\mathrm{p}^{2}$ : significance between good and poor sleepers in NCBP group

Secondly, the psychiatric condition and sleep quality of the patients were evaluated with only yes/no questions, not inventories based on numerical scales. Another common feature of these diseases is that there is a considerable overlap between their accompanying key symptoms, such as fatigue, myalgias, sleep disorders, and depression, which has led researchers to consider CSS, a state in which the central nervous system amplifies sensory input across many organ systems and causes a myriad of symptoms [33]. In light of the findings obtained from this study, NCBP, whose etiology has not yet been fully elucidated, has similar key symptoms to the other components of CSS. In addition, some studies in the literature showing the higher coexistence of CSS subgroups, including fibromyalgia, chronic pelvic pain, and irritable bowel syndrome in mastalgia patients compared to the normal population, led the researchers of this study to the idea that NCBP might also be a part of CSS [23, 30-32]. To the best of our knowledge, the current study is the first to analyze sleep quality in patients with NCBP and hypothesize that NCBP may not be a symptom itself but a part of a chronic pain syndrome, namely CSS.

It has been shown by various studies that disasters affecting communities including outbreaks of infectious diseases, earthquakes, and wars cause a socially noticeable sleep quality disorder by increasing the levels of stress and anxiety. Another important aspect of this study is that it was conducted during the COVID-19 pandemic, which is a considerable challenge to both patients and health-care workers. Although the disease has been 
Table 4 Correlation between the PSQI global score and clinical parameters of the study groups

\begin{tabular}{|c|c|c|c|c|}
\hline & \multicolumn{2}{|c|}{ Control group } & \multicolumn{2}{|c|}{ NCBP group } \\
\hline & $r$ & $p$ & $r$ & $p$ \\
\hline Age & 0.075 & $0.627^{*}$ & -0.216 & $0.020 *$ \\
\hline BMI & -0.161 & $0.297 *$ & 0.144 & $0.124 *$ \\
\hline HADs-total & -0.082 & 0.596 II & 0.550 & $<0.0019$ \\
\hline HADs-anxiety & 0.074 & $0.634 \mathscr{I}$ & 0.566 & $<0.0019$ \\
\hline HADs-depression & -0.168 & 0.275 II & 0.417 & $<0.0019$ \\
\hline \multicolumn{5}{|l|}{ McGill Pain Questionnaire } \\
\hline Sensory dimension & & & 0.295 & $\mathbf{0 . 0 0 1} 1$ \\
\hline Affective dimension & & & 0.275 & $\mathbf{0 . 0 0 3} q$ \\
\hline Total breast pain score & & & 0.308 & $\mathbf{0 . 0 0 1} 9$ \\
\hline VAS-pain & & & 0.660 & $<0.0019$ \\
\hline PPI & & & 0.516 & $<0.0019$ \\
\hline Nottingham Health Profile Part 1 & 0.563 & $<\mathbf{0 . 0 0 1} \mathbb{I}$ & 0.635 & $<0.0019$ \\
\hline Physical mobility & 0.599 & $<\mathbf{0 . 0 0 1}$ I & 0.522 & $<0.0019$ \\
\hline Pain & -0.263 & 0.084 II & 0.534 & $<0.001$ \\
\hline Sleep & 0.483 & 0.001 I & 0.417 & $<0.0019$ \\
\hline Energy & 0.650 & $<\mathbf{0 . 0 0 1}$ I & 0.405 & $<0.0019$ \\
\hline Social isolation & 0.387 & 0.010 $\mathscr{I}$ & 0.428 & $<0.0019$ \\
\hline Emotional reactions & 0.073 & $0.640 \mathbb{I}$ & 0.449 & $<0.0019$ \\
\hline Nottingham Health Profile Part 2 & 0.292 & $0.054 \mathscr{I}$ & 0.533 & $<0.0019$ \\
\hline
\end{tabular}

$B M I$, body mass index; $P S Q I$, Pittsburgh Sleep Quality Index; HADs, Hospital Anxiety and Depression Scale; VAS, visual analog scale; $P P I$, present pain intensity

*Pearson's correlation analysis; II Spearman's correlation analysis; r correlation coefficient. Statistically significant at $\mathrm{p}<0.05$. Statistically significant differences are indicated in bold sporadic for a long time and the government, where the study was conducted, did not set up severe rules limiting individual freedom and keeping social distancing to avoid the deterioration of COVID-19 pandemic, such a great public health emergency of international concern might influence the patient population characteristics seeking care for health problems. A universal lockdown as an epidemiological containment strategy may have unwanted results such as public anxiety around COVID-19 discouraging patients from seeking medical help. Considering that the lockdown is likely to affect characteristics of patients who sought care during this time may have been quite different from the general population of patients who would normally seek care outside of a pandemic, there is a pressing need to monitor several factors that may have played a role in determining the worsening of subjective sleep quality caused by these unprecedented changes in people's daily lives [34].

Several limitations of the study need to be acknowledged. Firstly, factors related to sleep disturbances were assessed in the patients with NCBP but not compared to a CBP group. Future studies need to evaluate the existence of sleep problems in the CBP group and compare the underlying causal relationships between the two BP groups. Second limitation that should be considered was the effects of COVID-19 pandemic on potentially heterogeneous patterns of changes in sleep in the given study population, given the complexity of conducting a study under complex multifaceted crises conditions. Although lockdown rules were not enforced in this area during the course of the study, a disaster that affected the rest of the world may have led to a change in the characteristics of patients admitted to hospital. Moreover, the sample size was relatively small in control group and it is also important to note that extensive exclusion criteria used to describe pure NCBP patients may introduce a selection bias. Taken together, these factors affect the generalizability of the results. In addition, since this was a crosssectional study, the patients' sleep status was not followed up after an appropriate therapy targeting both the pain itself and psychological status. Long-termed, case-control studies can be conducted to report the effect of psychoactive drugs and psychoeducative programs on the pain level and sleep problems of individuals suitable for treatment.

\section{Conclusion}

The findings of this study suggest that a considerable proportion of patients with NCBP, regardless of sensory or affective characteristics and trajectory of pain, experience significant sleep disturbances. Further studies should be 
conducted to evaluate the existence of CSS in NCBP patients to determine the optimal treatment approach.

Author contribution Concept - P.B., S.T.; design - P.B.; supervision - P.B.; resources - P.B.; data collection and/or processing - P.B., S.T.; physical examination: P.B.; analysis and/or interpretation - S.T.; literature search - P.B., S.T.; writing manuscript - P.B.; critical review - P.B., S.T.

Data availability Raw data were generated at Medipol University Medical Faculty General Surgery Department. Derived data supporting the findings of this study are available from the corresponding author (P. Basim) on request.

\section{Declarations}

Ethics approval Ethical approval for the study was received from the Research Ethics Committee of Medipol University (decision number: 10840098-604.01.01-E.15398/389).

Consent to participate Informed consent was obtained from all individual participants included in the study.

Consent for publication Both authors hereby declare that they participated in the study and in the development of the manuscript. They have read the final version and give their consent to be published in "Sleep and Breathing."

Conflict of interest The authors declare no competing interests.

\section{References}

1. Eren T, Aslan A, Ozemir IA, Baysal H, Sagiroglu J, Ekinci O, Alimoglu O (2016) Factors effecting mastalgia. Breast Care (Basel, Switzerland) 11(3):188-193. https://doi.org/10.1159/000444359

2. Kanat BH, Atmaca M, Girgin M, Ilhan YS, Bozdağ A, Özkan Z, Yazar FM, Emir S (2016) Effects of mastalgia in young women on quality of life, depression, and anxiety levels. Indian J Surg 78(2):96-99. https://doi.org/10.1007/s12262-015-1325-5

3. Smith RL, Pruthi S, Fitzpatrick LA (2004) Evaluation and management of breast pain. Mayo Clin Proc 79:353-372

4. Ader DN, Browne MW (1997) Prevalence and impact of cyclic mastalgia in a United States clinic-based sample. Am J Obstet Gynecol 177:126-132

5. Gateley CA, Maddox PR, Mansel RE, Hughes LE (1990) Mastalgia refractory to drug treatment. Br J Surg 77:1110-1112

6. Saghafi N, Rhkhshandeh H, Pourmoghadam N, Pourali L, Ghazanfarpour M, Behrooznia A, Vafisani F (2018) Effectiveness of Matricaria chamomilla (chamomile) extract on pain control of cyclic mastalgia: a double-blind randomized controlled trial. J Obst Gynecol 38:81-84. https://doi.org/10.1080/01443615.2017. 1322045

7. Groen JW, Grosfeld S, Wilschut JA, Bramer WM, Ernst MF, Mullender MM (2017) Cyclic and non-cyclic breast-pain: a systematic review on pain reduction, side effects, and quality of life for various treatments. Eur J Obstet Gynecol Reprod Biol 219:74-93. https://doi.org/10.1016/j.ejogrb.2017.10.018

8. Kyranou M, Paul SM, Dunn LB, Puntillo K, Aouizerat BE, Abrams G, Hamolsky D, West C, Neuhaus J, Cooper B,
Miaskowski C (2013) Differences in depression, anxiety, and quality of life between women with and without breast pain prior to breast cancer surgery. Eur J Oncol Nurs 17(2):190-195. https:// doi.org/10.1016/j.ejon.2012.06.001

9. Barton MB, Elmore JG, Fletcher SW (1999) Breast symptoms among women enrolled in a health maintenance organization: frequency, evaluation and outcome. Ann Intern Med 130:651-657. https://doi.org/10.7326/0003-4819-130-8-199904200-00005

10. Smallwood JA, Kye DA, Taylor I (1986) Mastalgia: is this commonly associated with operable breast cancer? Ann R Coll Surg Engl 68:262-263

11. Nie A, Wang C, Song Y, Xie X, Yang H, Chen H (2018) Prevalence and factors associated with disturbed sleep in outpatients with ankylosing spondylitis. Clin Rheumatol 37(8):2161-2168. https://doi.org/10.1007/s10067-018-4190-3

12. Gevirtz C (2007) Treating sleep disturbances in patients with chronic pain. Nursing 37(4):26-27. https://doi.org/10.1097/01. NURSE.0000266019.45858.7e

13 Van Onselen C, Aouizerat BE, Dunn LB, Paul SM, West C, Hamolsky D, Lee K, Melisko M, Neuhaus J, Miaskowski C (2013) Differences in sleep disturbance, fatigue and energy levels between women with and without breast pain prior to breast cancer surgery. Breast. 22(3):273-276. https://doi.org/10.1016/j.breast.2012.07. 007

14. Druce KL, Cordingley L, Short V, Moore S, Hellman B, James B, Lunt M, Kyle SD, Dixon WG, McBeth J (2018) Quality of life, sleep and rheumatoid arthritis (QUASAR): a protocol for a prospective UK mHealth study to investigate the relationship between sleep and quality of life in adults with rheumatoid arthritis. BMJ Open 8(1):e018752. https://doi.org/10.1136/bmjop en-2017-018752

15 Moldofsky H (2008) The significance of the sleeping-waking brain for the understanding of widespread musculoskeletal pain and fatigue in fibromyalgia syndrome and allied syndromes. Joint Bone Spine 75(4):397-402. https://doi.org/10.1016/j.jbspin.2008. 01.021

16 Cheatle MD, Foster S, Pinkett A, Lesneski M, Qu D, Dhingra L (2016) Assessing and managing sleep disturbance in patients with chronic pain. Anesthesiol Clin 34(2):379-393. https://doi.org/10. 1016/j.anclin.2016.01.007

17 Mathias JL, Cant ML, Burke ALJ (2018) Sleep disturbances and sleep disorders in adults living with chronic pain: a meta-analysis. Sleep Med 52:198-210. https://doi.org/10.1016/j.sleep.2018.05. 023

18 Kücükdeveci AA, McKenna SP, Kutlay S, Gürsel Y, Whalley D, Arasil T (2000) The development and psychometric assessment of the Turkish version of the Nottingham Health Profile. Int J Rehabil Res 23(1):31-38. https://doi.org/10.1097/00004356-20002 3010-00004

19 Zigmond AS, Snaith RP (1983) The hospital anxiety and depression scale. Acta Psychiatr Scand 67(6):361-370. https://doi.org/ 10.1111/j.1600-0447.1983.tb09716.x

20. Instruments: Pittsburgh Sleep Quality Index (PSQI). University of Pittsburgh Sleep Medicine Institute. University of Pittsburgh. https://www.sleep.pitt.edu/instruments/. Retrieved September 20, 2020

21 Melzack R (1987) The short-form McGill Pain Questionnaire. Pain. 30(2):191-197. https://doi.org/10.1016/0304-3959(87) 91074-8

22 Preece PE, Mansel RE, Hughes LE (1978) Mastalgia: psychoneurosis or organic disease? Br Med J 1(6104):29-30. https://doi.org/ 10.1136/bmj.1.6104.29

23 Johnson KM, Bradley KA, Bush K, Gardella C, Dobie DJ, Laya MB (2006) Frequency of mastalgia among women veterans. Association with psychiatric conditions and unexplained pain 
syndromes. J Gen Intern Med 21(Suppl 3):S70-S75. https://doi. org/10.1111/j.1525-1497.2006.00378.x

24 Colegrave S, Holcombe C, Salmon P (2001) Psychological characteristics of women presenting with breast pain. J Psychosom Res 50(6):303-307. https://doi.org/10.1016/s0022-3999(01)00196-9

25. Hacimusalar Y, Talih T, Karaaslan O (2020) How do health anxiety, somatosensory amplification, and depression levels relate to non-cyclical mastalgia? A case-control study. Indian J Surg 82:578-584. https://doi.org/10.1007/s12262-019-02014-y

26. Khan HN, Rampaul R, Blamey RW (2004) Local anaesthetic and steroid combined injection therapy in the management of noncyclical mastalgia. Breast 13(2):129-132. https://doi.org/10. 1016/j.breast.2003.09.010

27 Öztürk AB, Özenlı Y, Öztürk SB, Önel S, Söker S, Seydaoglu $G$ (2015) The effect of psychoeducation on anxiety and pain in patients with mastalgia. Nord J Psychiatry 69(5):380-385. https:// doi.org/10.3109/08039488.2014.989260

28 Seto A, Han X, Price LL, Harvey WF, Bannuru RR, Wang C (2019) The role of personality in patients with fibromyalgia. Clin Rheumatol 38(1):149-157. https://doi.org/10.1007/ s10067-018-4316-7

29. Martins RJ, Garbin CAS, Garcia AR, Garbin AJÍ, Miguel N (2010) Stress levels and quality of sleep in subjects with temporomandibular joint dysfunction. Rev Odonto Ciênc 25(1):32-36. https://doi.org/10.1590/S1980-65232010000100007
30 Cosar E, ÇakırGüngör A, Gencer M, Uysal A, Hacivelioğlu SO, Özkan A, Şen HM (2014) Sleep disturbance among women with chronic pelvic pain. Int J Gynaecol Obstet 126(3):232-234. https://doi.org/10.1016/j.ijgo.2014.03.034

31. Navabi S, Gorrepati VS, Yadav S, Chintanaboina J, Maher S, Demuth P, Stern B, Stuart A, Tinsley A, Clarke K, Williams ED, Coates MD (2018) Influences and impact of anxiety and depression in the setting of inflammatory bowel disease. Inflamm Bowel Dis 24(11):2303-2308. https://doi.org/10.1093/ibd/izy 143

32 Genc V, Genc A, Ustuner E, Dusunceli EB, Oztuna D, Bayar S, Kurtais Y (2011) Is there an association between mastalgia and fibromyalgia? Comparing prevalence and symptom severity. Breast 20(4):314-318. https://doi.org/10.1016/j.breast.2011.01. 016

33 Cuesta-Vargas AI, Roldan-Jimenez C, Pajares B, Alba E, On behalf of the Club_CAM (2018) Central sensitization in breast cancer survivors. J Appl Behav Res 23:e12120

34. Jahrami H, BaHammam AS, Bragazzi NL, Saif Z, Faris M, Vitiello MV (2021) Sleep problems during the COVID-19 pandemic by population: a systematic review and meta-analysis. J Clin Sleep Med 17(2):299-313

Publisher's note Springer Nature remains neutral with regard to jurisdictional claims in published maps and institutional affiliations. 